\title{
CDX2 Regulates Multidrug Resistance 1 Gene Expression in Malignant Intestinal Epithelium
}

Yuji Takakura ${ }^{1}$, Takao Hinoi ${ }^{2}$, Naohide Oue ${ }^{3}$, Tatsunari Sasada ${ }^{1}$, Yasuo Kawaguchi ${ }^{1}$, Masazumi Okajima ${ }^{2}$, Aytekin Akyol ${ }^{4}$, Eric R. Fearon ${ }^{4}$, Wataru Yasui ${ }^{3}$, and Hideki Ohdan ${ }^{1}$

\section{Abstract}

The caudal-related homeobox transcription factor CDX2 has a key role in intestinal development and differentiation. CDX2 heterozygous mutant mice develop colonic polyps, and loss of CDX2 expression is seen in a subset of colon carcinomas in humans. Ectopic CDX2 expression in the stomach of transgenic mice promotes intestinal metaplasia, and CDX2 expression is frequently detected in intestinal metaplasia in the stomach and esophagus. We sought to define CDX2-regulated genes to enhance knowledge of CDX2 function. HT-29 colorectal cancer cells have minimal endogenous CDX2 expression, and HT-29 cells with ectopic CDX2 expression were generated. Microarray-based gene expression studies revealed that the Multidrug Resistance 1 (MDR1/P-glycoprotein/ABCB1) gene was activated by CDX2. Evidence that the MDR1 gene was a direct transcriptional target of CDX2 was obtained, including analyses with MDR1 reporter gene constructs and chromatin immunoprecipitation assays. RNA interference-mediated inhibition of CDX2 decreased endogenous $M D R 1$ expression. In various colorectal cancer cell lines and human tissues, endogenous MDR1 expression was well correlated to CDX2 expression. Overexpression of CDX2 in HT-29 cells revealed increased resistance to the known substrate of MDR1, vincristine and paclitaxel, which was reversed by an MDR1 inhibitor, verapamil. These data indicate that CDX2 directly regulates MDR1 gene expression through binding to elements in the promoter region. Thus, CDX2 is probably important for basal expression of MDR1, regulating drug excretion and absorption in the lower gastrointestinal tract, as well as for multidrug resistance to chemotherapy reagent in CDX2-positive gastrointestinal cancers. Cancer Res; 70(17); 6767-78. @2010 AACR.

\section{Introduction}

There has long been great interest in defining critical regulatory factors that direct cell fate determination and differentiation in normal and cancer tissues. In mammals, the CDX1 and CDX2 homeobox transcription factors apparently have critical functions in intestinal development, differentiation, and maintenance of the intestinal phenotype $(1,2)$. CDX1 and CDX2 proteins show significant homology, particularly in their homeobox DNA-binding domains, to the protein product of the Drosophila caudal gene, a key regulator of

\footnotetext{
Authors' Affiliations: Departments of ${ }^{1}$ Surgery, ${ }^{2}$ Endoscopic Surgery and Surgical Science, and ${ }^{3}$ Molecular Pathology, Division of Frontier Medical Science, Programs for Biomedical Research, Graduate Schoo of Biomedical Science, Hiroshima University, Hiroshima, Japan; and ${ }^{4}$ Division of Molecular Medicine and Genetics, Departments of Internal Medicine, Human Genetics, and Pathology, University of Michigan Medical School, Ann Arbor, Michigan

Note: Supplementary data for this article are available at Cancer Research Online (http://cancerres.aacrjournals.org/).

Present address for A. Akyol: Hacettepe University School of Medicine, Department of Pathology, Ankara, Turkey.

Corresponding Author: Takao Hinoi, Department of Endoscopic Surgery and Surgical Science, Hiroshima Universtiy, 1-2-3 Kasumi, Minami-ku, Hiroshima, 734-8551, Japan. Phone: 81-82-257-5222; Fax: 81-82-2575224; E-mail: thinoi@hiroshima-u.ac.jp.

doi: 10.1158/0008-5472.CAN-09-4701
}

C2010 American Association for Cancer Research. anterior-posterior regional identity $(1,3,4)$. Mouse $C d x 1$ and $C d x 2$ genes are quite broadly expressed during early embryonic development. Recent studies indicated that $\mathrm{Cdx} 2$ is one of the earliest transcription factors essential for formation and maintenance of the trophectoderm lineage in mouse embryos $(5,6)$. However, in later stages of development and in normal adult tissues, expression of the genes is apparently restricted to epithelium of the small intestine and colon (1). In support of the view that CDX proteins play key roles in regulating proliferation and intestinal cell fate, mice with constitutional inactivating mutations in one $C d x 2$ allele $(C d x 2 \pm)$ developed multiple polyps in the proximal colon (7-10). The epithelial cells in these polyps often lose intestinal differentiation features, displaying areas of stratified squamous epithelium similar to that in forestomach and distal esophagus as well as areas resembling normal gastric mucosa $(7,11)$. Ectopic expression of $C d x 2$ in the gastric mucosa of transgenic mice was reported to induce intestinal metaplasia $(12,13)$. In humans, loss of the $C D X 1$ and/or $C D X 2$ gene and protein expression was observed in a subset of primary colorectal cancers (CRC) and cancer cell lines (14), usually in poorly differentiated CRCs (15). Aberrant (ectopic) expression of CDX2 is detected frequently in intestinal metaplasia of the stomach $(16,17)$.

Our prior efforts to identify CDX2-regulated genes indicated that liver intestine-cadherin (LI-cadherin) and hephaestin 
(HEPH) were likely key molecules regulated by CDX2 in normal and malignant gastrointestinal epithelium $(16,18)$.

Here, we report on further studies to implicate CDX2 in regulating the expression of intestinal-specific genes by using high-density oligonucleotide microarrays as a starting point to identify potential CDX2-regulated genes in HT-29, a CRC cell line with significantly decreased endogenous CDX2 expression. In HT-29 cell line engineered to express CDX2 ectopically, the gene for Multidrug Resistance 1 (MDRI) was strongly activated.

Of some potential interest, $M D R 1$ was originally identified as an overexpressed and amplified gene in multiple drugresistant cells, and its product, P-glycoprotein, seems to play a critical role in drug resistance (19). We provide data here implicating CDX2 as an important factor in regulation of $M D R 1$ expression in gastrointestinal tissues.

\section{Materials and Methods}

\section{Plasmids}

A full-length, wild-type $C D X 2$ and $C D X 1$ allele were amplified by PCR using hexamer-primed complementary DNA (cDNA) from normal human colon tissue as a template. Sequence coding Flag epitope was added to the $5^{\prime}$ ends of $C D X 1$ allele. The $C D X 2$ and Flag- $C D X 1$ allele were inserted into the multiple cloning site of the retroviral expression vector pPGS-CMV-CITE-neo (pPGS-neo, provided by G. Nabal, $\mathrm{NIH}$, Bethesda, MD) to generate pPGS-CDX2. The full-length, wild-type $C D X 2$ allele was also subcloned into the retroviral vector pBabe-Puro ER (provided by A. Friedman, Johns Hopkins Oncology Center, Baltimore, MD; ref. 20) to generate pCDX2-ER. The pCDX2-ER vector encodes a chimeric protein in which full-length CDX2 sequences are fused upstream of a mutated estrogen receptor (ER) ligand-binding domain. The mutated ER ligand-binding domain no longer binds estrogen, but retains the ability to bind tamoxifen. Fragments from human MDR1 and glyceraldehyde-3-phosphate dehydrogenase $(G A P D H)$ genes were generated by PCR using hexamerprimed cDNA from Caco2 cells as a template (16). A 309-bp fragment of MDR1 cDNA was amplified using forward primer 5'-CAGTGAACTCTGACTCTATGAGATG-3' and reverse primer $5^{\prime}$-AGCAAGGCAGTCAGTTACAGTCC- $3{ }^{\prime}$. The MDR1 and GAPDH cDNA fragments were subcloned into the pGEM-T Easy Vector (Promega). Genomic DNA sequences from the promoter regions of the human $M D R 1$ gene were cloned by PCR, using genomic DNA purified from DLD1 cells as a template, with the reverse primer $5^{\prime}$-GGCTCGAGGAAACAGGTTGAATTTCCAGG-3' and the following forward primers: 5'-GCGGGTACCAGGCATTTAGCCTACTAGTG-3' (from -4,003), $5^{\prime}$-ATGGTACCACATGTGAAAGGGTGGAGAGTG-3' (from -3,414), 5' - CCGGTACCATGTCAGTGgAgCAAAGAAATG-3' (from -1,711), and 5' -CCGGTACCGTGAACAATGCTGTACACTTGC-3' (from $-1,422)$. The PCR products were digested with Kpnl and Xhol (sites underlined in the primers) and subcloned into pGL4.10 [luc2] vector (Promega). PCR-based approaches were used to introduce mutations into the presumptive CDX2-binding sites in the pGL4.10-MDR1 $(-4,203 /+50)$ reporter gene construct. Sequence of presumptive CDX2 binding site A (ATTTATG) and B (TTTTATG) were changed to ACCTGCG and TCCTGCG in the primer using the primers: 5'-GCGGTACCAGGCATTTAGCCTACTAGTGTAATTTCCGCAGGTC- $3^{\prime}$ and $5^{\prime}$-GAGCGGGCTTCTCAGATGATATGTGCTTTTCACTCTGTGC-3' (for binding site A), and $5^{\prime}$-GCGGGTACCAGGCATTTAGCCTACTAGTG-3', $5^{\prime}$ GCATGTCCTTCATACGCAGGAATCATTACATGTG-3', $5^{\prime}$-GCGTATGAAGGACATGTGATGATAGGGG-3', and 5'-GGGCTTCTCAGATGATATGTGCTTTTCACTC-3' (for binding site B). All fragments generated by PCR were verified by automated sequencing of the respective plasmid constructs. Plasmid pGL4.74 [hRluc/TK] vector (Promega) was used as control for transfection efficiency in reporter assays.

\section{Cell culture and retrovirus infections}

The amphotropic Phoenix packaging cell line was provided by G. Nolan (Stanford University, Stanford, CA). All other cell lines were obtained from the American Type Culture Collection in 1998 to 2000. Frozen stock was made immediately and stored in liquid nitrogen until the initiation of this study. After thawing frozen stock, the cells were kept at low passage throughout the study. The cell morphology was monitored by microscopy and confirmed that their morphologic images were maintained in comparison with the original morphologic images. Details of cell culture conditions were previously described (16). The Phoenix packaging cells were transfected with retroviral expression constructs (pPGS-CDX2, pPGS-neo, pPGS-Flag-CDX1, and pCDX2-ER); the supernatant containing nonreplicating amphotropic virus was harvested as previously described (16). HT-29 cells were infected with virus, selected, and maintained in media containing G418 (Invitrogen) or Puromycin (Sigma). In HT-29 cells expressing the CDX2-ER fusion protein (HT-29/CDX2-ER), CDX2 function was activated by addition of 4-hydroxytamoxifen (4-OHT; Sigma) to the growth medium at a final concentration of 500 $\mathrm{nmol} / \mathrm{L}$. To assess MDR1 as a direct CDX2-regulated target gene, HT-29/CDX2-ER cells were treated with the protein synthesis inhibitor cycloheximide (Sigma) at a concentration of $1 \mu \mathrm{g} / \mathrm{mL}$.

\section{Complementary RNA synthesis and gene expression profiling}

Total RNA was prepared by Trizol (Invitrogen) extraction and purification with the RNeasy Cleanup kit (Qiagen). Gene expression analyses were performed with GeneChip Human Genome U95Av2 and U133A (Affymetrix, Inc.) following supplier instructions. Affymetrix arrays were scanned using the GeneArray scanner (Affymetrix); image analysis was performed with the GeneChip 4.0 software (Affymetrix).

\section{Northern blot analysis}

For each sample, $10 \mu \mathrm{g}$ of total RNA were fractionated by electrophoresis and transferred to a Zeta-Probe GT membrane (Bio-Rad Laboratories). Hybridization was performed using ${ }^{32} \mathrm{P}$-radiolabeled cloned cDNA fragments of $M D R 1$, as previously described (16). The membrane was stripped and reprobed with $G A P D H$ cDNA to confirm equivalent loading and RNA transfer. 


\section{Western blot assays}

Western blot analysis was performed essentially as previously described (16). Anti-CDX2 mouse monoclonal antibodies (clone 7C7/D4, BioGenex Laboratories, Inc.), antihuman MDR1 monoclonal antibody (clone C219, Calbiochem), and anti-Flag M2 monoclonal antibody (Sigma) were used at $1: 10,000,1: 50$, and 1:500 dilutions, respectively. The membrane was stripped and reprobed with an anti- $\beta$-actin monoclonal antibody (clone AC-15; Sigma) to verify loading and transfer.

\section{RNA interference}

Two small interfering RNA (siRNA) duplexes targeting CDX2 (5' -AACCAGGACGAAAGACAAAUA-3', CDX2 siRNA-1; and $5^{\prime}$-AAGCCUCAGUGUCUGGCUCUG-3', CDX2 siRNA-2) and a nonsilencing siRNA duplex ( $5^{\prime}$-AAUUCUCCGAACGUGUCACGU-3') were synthesized by Qiagen-Xeragon. Cells were cultured in antibiotic-free medium for 24 hours before transfection. They were then transfected with siRNA (340 pmol) using DharmaFECT1 (Dharmacon). Silencing was examined 72 hours after transfection. Each sample was reverse transcribed using the ReverTra Ace qPCR RT kit (Toyobo) following supplier protocols. Quantitative PCR (qPCR) analysis was performed on an ABI 7500HT with Power SYBR Green PCR Master Mix (Applied Biosystems). MDR1 primers were as follows: forward, $5^{\prime}$-ATAATGCGACAGGAGATAGG-3' ${ }^{\prime}$; and reverse, $5^{\prime}$-CCAAAATCACAAGGGTTAGC- $3^{\prime}$. GAPDH primers were as follows: forward, $5^{\prime}$-TTGAGGTCAATGAAGGGG-3'; and reverse, $5^{\prime}$-GAAGGTGAAGGTCGGAGTC- $3^{\prime}$. All experiments were conducted three times. Human GAPDH was measured as the internal control.

\section{Reporter gene assays}

At 48 hours before transfection, cells were seeded in $35-\mathrm{mm}$ dishes. HT29/PGS-CDX2 and HT29/PGS-neo cells were transfected at $50 \%$ to $80 \%$ confluency with $4 \mu \mathrm{L}$ of Lipofectamine 2000 (Invitrogen), $0.5 \mu \mathrm{g}$ of pGL4.10 reporter gene construct, and $0.05 \mu \mathrm{g}$ of control plasmid pGL4.74. At 40 hours after transfection, cells were collected and resuspended in passive lysis buffer (Promega). Luciferase activity was determined with a dual luciferase assay system (GloMax96 Microplate Luminometer, Promega).

\section{Chromatin immunoprecipitation assay}

The chromatin immunoprecipitation (ChIP) assays were performed using the ChIP-IT Express kit (Active Motif) following supplier instructions. Chromatin extracts containing DNA fragments (average size, $500 \mathrm{bp}$ ) were immunoprecipitated using $2 \mu \mathrm{g}$ monoclonal anti-CDX2 antibody (7C7/D4) or $2 \mu \mathrm{g}$ nonimmunized mouse IgG whole molecule (negative control, Active Motif). Fragments (200 bp) of the MDR1 promoter regions were PCR amplified using the primers $5^{\prime}$ CCTGGGAGACAGAGTAATAC- $3^{\prime}$ (forward) and $5^{\prime}$ CAAACTGGACAGAGACTTATAC-3' (reverse; -4,100/-3,882, including binding site A), and $5^{\prime}$-ATCCCCTATCAAGTACAGTC-3' (forward) and 5' ${ }^{\prime}$-CTCAGTCCAAAGAGCAAGAC$3^{\prime}$ (reverse; $-3,482 /-3,296$, including binding site $\mathrm{B}$ ). As a negative control, a .4-kb DNA fragment from exon 3 of the $C D X 1$ gene was amplified by PCR using previously described primers (18). Each immunoprecipitated DNA sample was quantified using the average of duplicate qPCRs. All ChIPqPCR signals were normalized to the input (labeled as IP/ input). Each primer gave a single product of the right size, as confirmed by agarose gel electrophoresis.

\section{Immunohistochemical staining}

Formalin-fixed, paraffin-embedded tissues were stained using the avidin-biotin complex method as previously described (16). Mouse monoclonal anti-CDX2 antibody 7C7/D4 and mouse monoclonal anti-MDR1 antibody (clone C494; Zymed Laboratories) were used at 1:1,000 and 1:10 dilution, respectively.

\section{Cytotoxicity assay}

Paclitaxel and verapamil were purchased from Sigma, and 5-fluorouracil was provided by Kyowa Hakko Kogyo Co. Ltd. Doxorubicin and vincristine were provided by Nippon Kayaku. Camptothecin and cisplatin were purchased from LKT Laboratories. MTT cytotoxicity assay was used to examine cell survival after exposure to chemotherapeutic agents. Cells were seeded at 5,000 cells/100 $\mu \mathrm{L}$ per well in 96-well microtiter plates. After a 48-hour incubation period, cells were treated with a range of concentrations of each chemotherapeutic agent. To examine the effect of verapamil, a known P-glycoprotein inhibitor (21), $2 \mu \mathrm{mol} / \mathrm{L}$ were administered together with each chemotherapeutic agent. A pilot experiment showed that this concentration was not cytotoxic to HT-29/PGS-CDX2 or HT-29/PGS-neo cells (data not shown). After 72 hours, $10 \mu \mathrm{L}$ of MTT dye $(5 \mathrm{mg} / \mathrm{mL})$ was added to each well, and plates were incubated for 4 hours at $37^{\circ} \mathrm{C}$ in a humidified $5 \% \mathrm{CO}_{2}$ atmosphere. Dark blue formazan crystals formed by live cells were dissolved in $100 \mu \mathrm{L}$ of solubilization solution (10\% SDS in $0.01 \mathrm{~mol} / \mathrm{L} \mathrm{HCl}$ ). Absorbance in individual wells was determined at $570 \mathrm{~nm}$ using an MTP-300 microplate reader (CORONA Electric Co. Ltd.). Results were expressed in terms of the concentration required to inhibit cell growth by $50 \%$ relative to nontreated cells $\left[\mathrm{IC}_{50}(72 \mathrm{~h})\right]$.

\section{Results}

\section{CDX2 and MDR1 expression are correlated in colon carcinoma cells}

Similar to a few selected other human CRC cell lines, the HT-29 line shows very low endogenous CDX2 expression (22). To identify candidate CDX2-regulated genes, we generated polyclonal populations of HT-29 CRC cells ectopically expressing CDX2, by infecting the cells with replicationdefective retroviruses carrying full-length human $C D X 2$ cDNA (Fig. 1A). Comparison of gene expression in the HT-29/PGSCDX2 cells versus control populations (HT-29/PGS-neo) was performed using microarrays with focus on the MDR1 $(A B C B 1)$ gene. Affymetrix data indicated that $M D R 1$ gene expression was upregulated by CDX2 by roughly 31.14-fold in HT-29 cells (Fig. 1A). Northern and Western blot studies confirmed robust induction of MDR1 transcripts and protein in HT-29/PGS-CDX2 cells (Fig. 1B). To determine whether MDR1 is a selective CDX2 target, we also generated polyclonal 


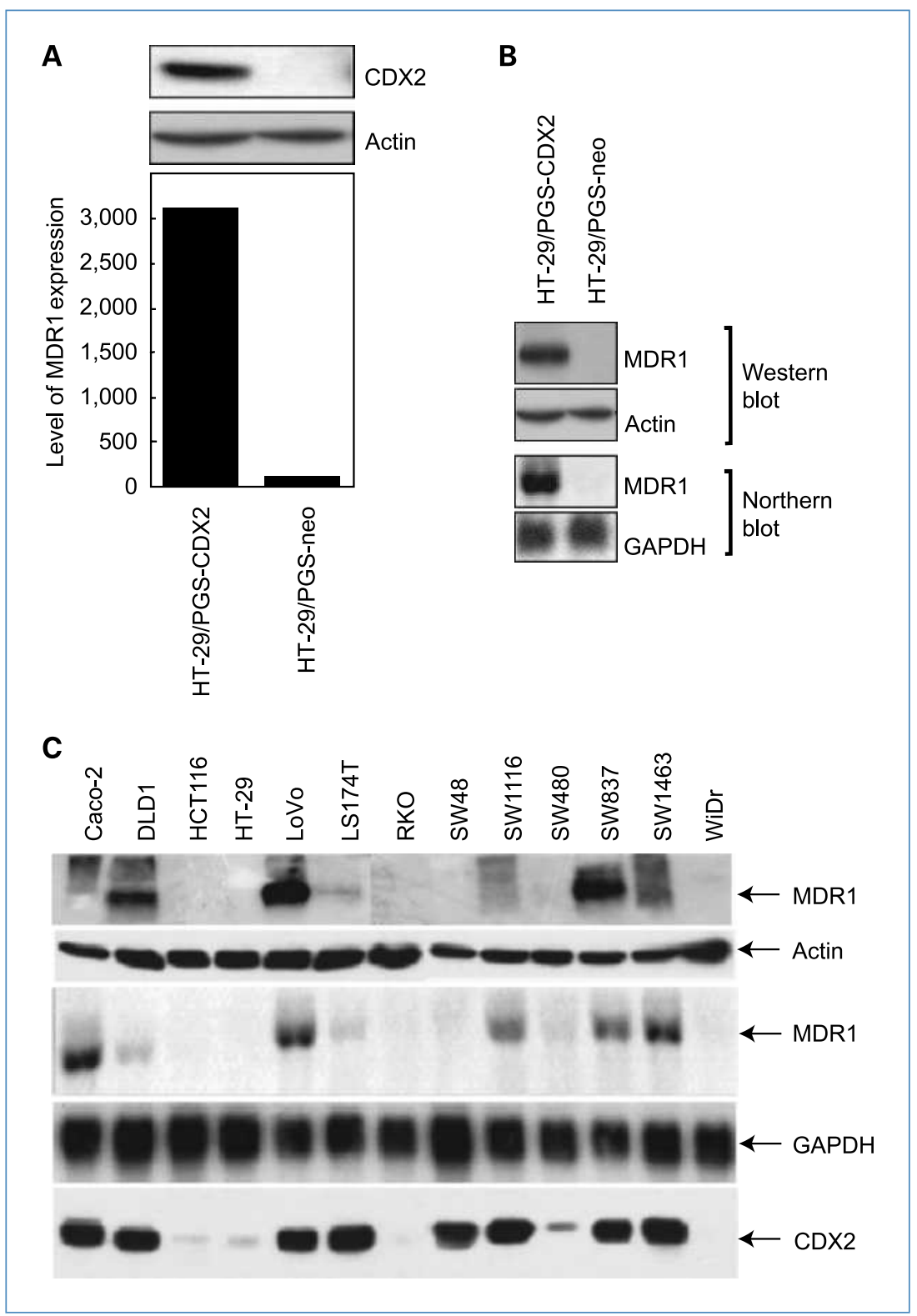

Figure 1. CDX2 activates MDR1 expression in HT-29 cells. A, top, a monoclonal anti-CDX2 antibody detects the roughly $40-\mathrm{kDa}$ CDX2 protein in HT-29/PGS-CDX2 cells but not in HT-29/PGS-neo cells. A, bottom, relative level of MDR1 gene expression in HT-29/PGS-CDX2 and HT-29/PGS-neo in Affymetrix microarray studies. B, Northern and Western blot analysis detects $M D R 1$ transcripts and products in HT-29/PGS-CDX2 with low or absent MDR1 expression in HT-29/PGS-neo cells. In Western blot analysis, a mouse monoclonal anti-MDR1 antibody detects the roughly $170-\mathrm{kDa} M D R 1$ product in HT-29/PGS-CDX2 cells but not in HT-29/PGS-neo cells. C, expression of CDX2 and MDR1 in 13 CRC cell lines. In the indicated $13 \mathrm{CRC}$ cell lines, Western blot analyses of MDR1 and CDX2 expression were performed using a mouse monoclonal antibody against human MDR1 and a mouse monoclonal antibody against human CDX2. The membranes were stripped and reprobed with a monoclonal antibody against $\beta$-actin to verify loading and transfer. Northern blot analysis of MDR1 expression was performed using an MDR1 cDNA probe. The membrane was stripped and reprobed with a GAPDH cDNA probe to verify loading and transfer.

populations of HT-29 cells ectopically expressing CDX1 (HT29/PGS-Flag-CDX1). In this cell line, MDR1 expression was not induced by overexpression of CDX1 (Supplementary Fig. S1).

To assess the correlation between endogenous $C D X 2$ and MDR1 expression in other CRC cell lines, Northern and Western blot analyses were performed on 12 additional lines. MDR1 protein expression was detected in six cell lines with high levels of MDR1 transcripts. In all of these cell lines, strong CDX2 expression was observed (Fig. 1C, lanes 1, 2, 5, 9, 11, and 12, 5, 9, 11, and 12). However, none of the cell lines with weak or undetectable CDX2 expression had detectable MDR1 transcripts or protein.

\section{The MDRI gene is a primary target of CDX2 activity}

To better assess the relationship between CDX2 function and $M D R 1$ gene expression, we studied $M D R 1$ expression in an HT-29-derived line with tightly regulated CDX2 activity. We used a polyclonal HT-29 cell line that had been transduced with a vector encoding a chimeric CDX2-ER fusion protein. In the chimeric CDX2-ER protein, full-length CDX2 sequences are present upstream of a mutated ER ligandbinding domain. The mutant ER ligand-binding domain is capable of binding to 4-OHT, but not estrogen. Expression of the CDX2-ER fusion protein in HT-29/CDX2-ER polyclonal cell line was confirmed (data not shown). Treatment of HT29/CDX2-ER cell line with 4-OHT strongly induced MDR1 expression within 12 hours, with further increased expression up to day 2 of 4-OHT treatment (Fig. 2A). Consistent with the notion that $M D R 1$ is a direct or primary target gene regulated by CDX2, blockade of new protein synthesis by cycloheximide treatment did not inhibit induction of MDRI 
transcripts at the 12-hour time point (Fig. 2B). However, as expected, cycloheximide treatment blocked induction of MDR1 protein expression in 4-OHT-treated HT-29/CDX2ER cells (Fig. 2B).

\section{Inhibition of CDX2 by RNA interference results in the downregulation of $M D R I$ in colon cancer cells}

To determine whether CDX2 is necessary for MDR1 expression in mammalian cells, we analyzed the effect of inhibiting CDX2 expression by RNA interference in the level of MDR1 expression. DLD-1, a CRC cell line with high endogenous CDX2 and MDR1 expression, was used. CDX2-specific siRNAs significantly suppressed CDX2 protein expression 3 days after transfection, and expression of $M D R 1$ transcript was downregulated roughly $50 \%$ by CDX2 siRNAs in DLD1 compared with its levels in parental and control siRNAtreated cells (Fig. 2C). These data indicate that CDX2 is involved in maintaining $M D R 1$ gene expression in gastrointestinal cell lines.

\section{The $5^{\prime}$-flanking region of the $M D R I$ gene contains a} CDX2-responsive element

To identify potential CDX2-binding sites in the MDR1 promoter region, genomic sequences immediately $5^{\prime}$ to the apparent transcription start site were searched, using a consensus-binding element for the $\mathrm{Cdx}$ A chicken caudalrelated protein $\left(5^{\prime}-\mathrm{A}, \mathrm{A} / \mathrm{T}, \mathrm{T}, \mathrm{A} / \mathrm{T}, \mathrm{A}, \mathrm{T}, \mathrm{A} / \mathrm{G}-3^{\prime}\right.$; ref. 23$)$ and a previously described search algorithm (24). Four candidate CDX2-binding sites were found in the -4.0 -kb region upstream of the presumptive transcription initiation sites: site A ( $5^{\prime}$-ATTTATG- $3^{\prime}$, from $-3,974$ to $\left.-3,980\right)$, site B $\left(5^{\prime}\right.$ TTTTATG- $3^{\prime}$, from $-3,421$ to $\left.-3,427\right)$, site C ( $5^{\prime}$-TTTTATG$3^{\prime}$, from $-1,489$ to $\left.-1,495\right)$, and site D ( $5^{\prime}$-ATTTATG- $3^{\prime}$, from $-1,463$ to $-1,469$; Fig. $3 A$ ). To assess the role of these presumptive CDX2-binding sites in regulating MDR1 transcription, several reporter gene constructs were generated (Fig. 3A). Reporter gene constructs containing $4.0 \mathrm{~kb}$ of a $5^{\prime}$-flanking sequence $(-4,003 /+50)$ from the MDR1 gene showed strong activity in the HT29/PGS-CDX2 cell lines (Fig. 3B).
Figure 2. The MDR1 gene is a primary target of CDX2 action. $\mathrm{A}$, time course of MDR1 gene induction in response to activation of a CDX2-ER fusion protein by 4-OHT. B, induction of MDR1 transcript in response to activation of a CDX2-ER fusion protein by $4-\mathrm{OHT}$ is not inhibited by the protein synthesis inhibitor cycloheximide, but protein synthesis is blocked. C, inhibition of CDX2 expression by siRNA targeting leads to decreased MDR1 expression in CRC cell line DLD1. Assays were performed in triplicate; columns, mean; bars, SD.

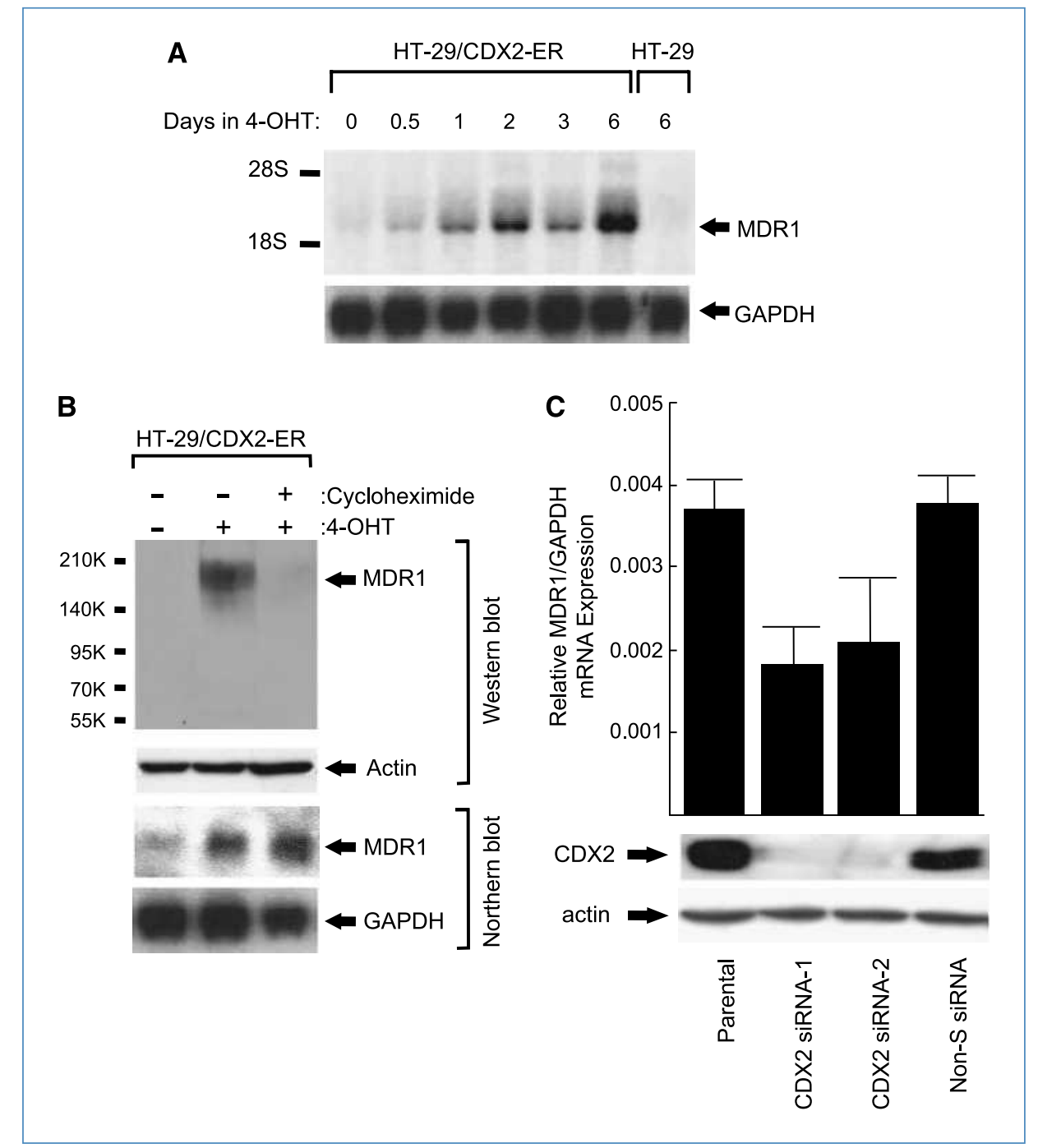




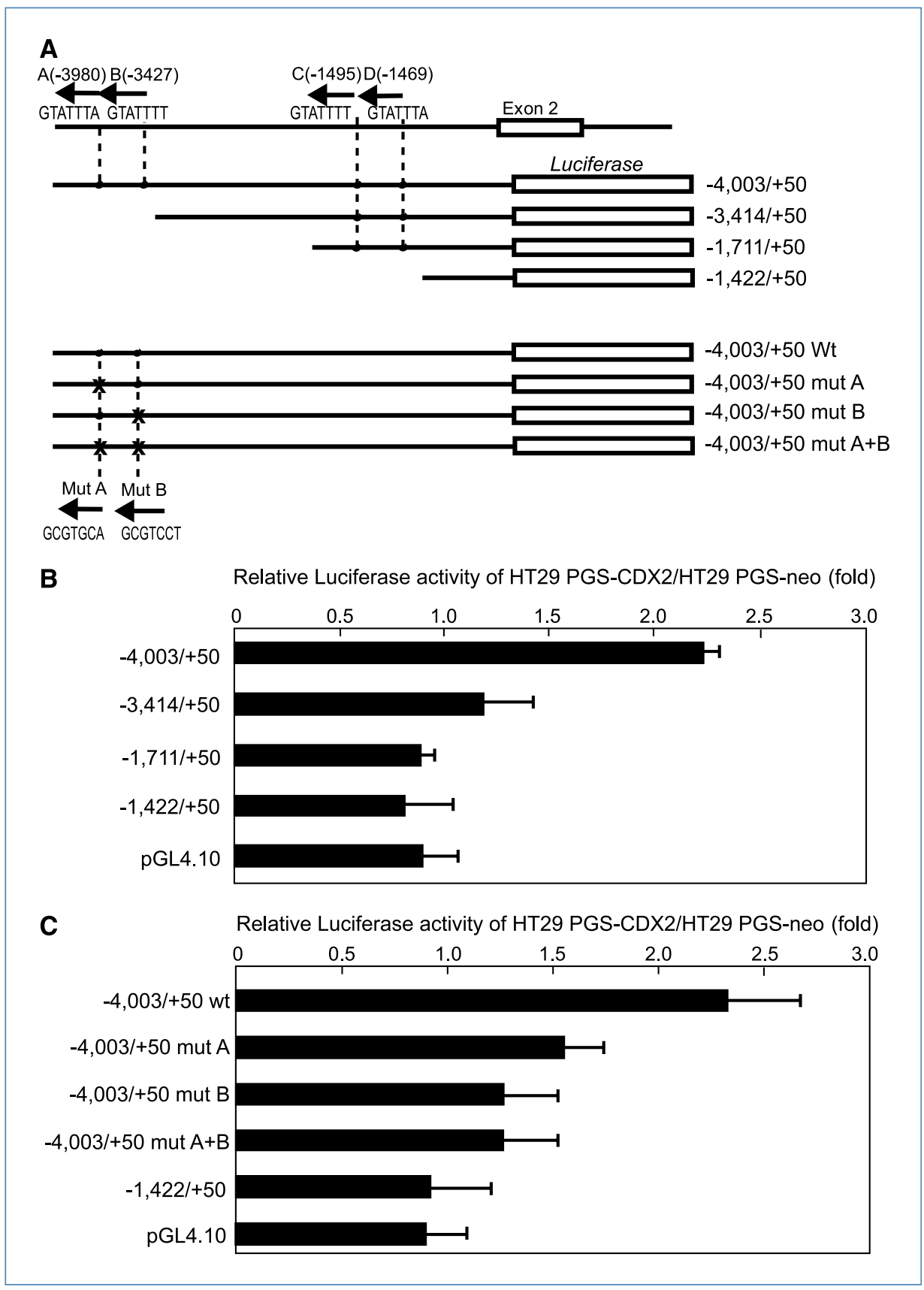

Figure 3. Localization of regulatory elements and CDX2 binding sites in the $5^{\prime}$-flanking region of the MDR1 gene. A, schematic representation of the $5^{\prime}$-flanking region of the MDR1 gene and MDR1 reporter gene constructs.

The location and sequence of four consensus CDX2-binding sites in the $5^{\prime}$-flanking region of MDR1 are indicated. The direction of the arrows indicates the strand on which the candidate CDX2-binding element was found (i.e., sense or antisense). The MDR1 genomic DNA sequences present in the reporter gene vectors are indicated. Localized mutations in the candidate CDX2-binding sites (i.e., site $A$ and $B$ ) were introduced into the $-4,003 /+50$ construct as noted (bottom), and the series of constructs generated is shown. $\mathrm{B}$, key sequences for MDR1 transcription in CDX2-expressing cell lines reside between bp $-4,003$ and $-3,414$. Columns, mean values of the luciferase activity ratio in HT29/PGS-CDX2 cells to that in HT29/PGS-neo cells; bars, SD. $\mathrm{C}, \mathrm{CDX} 2$ candidate binding sites $\mathrm{A}$ and $\mathrm{B}$ play critical roles in MDR1 transcription. All assays were performed in triplicate; columns, mean of luciferase activity ratio; bars, SD.

All the MDR1 reporter gene constructs with deletions downstream of the $4.0-\mathrm{kb}$ pair site showed decreased activity in HT29/PGS-CDX2 cell lines; thus, sequences between -3.4 - and $-4.0-\mathrm{kb}$ pairs are important in activating MDR1 transcription. Analysis of single and multiple mutations in the presumptive CDX2-binding sites in this region using HT29/PGS-CDX2 and HT29/PGS-neo showed that the presumptive CDX2-binding sites A and B play crucial roles in activating $M D R 1$ transcription (Fig. 3C).

\section{CDX2 binds to elements in the $5^{\prime}$-flanking region of the MDRI gene}

As previously noted, using the HT-29/CDX-ER cell line and the protein synthesis inhibitor cycloheximide, we found that the MDR1 gene was a direct or primary target of CDX2. Additionally, MDR1 reporter gene studies with localized mutations of CDX2-binding sites implied that CDX2 plays a major role in activating MDR1 transcription by binding to one or more sites in the MDR1 proximal promoter region. To confirm that CDX2 does indeed bind 
directly to sequences in the $M D R 1$ promoter region, we undertook ChIP assays using HT-29/CDX-ER cells. Before treatment of HT-29/CDX-ER cells with 4-OHT, the CDX2-ER fusion protein was expressed but remained inactive in the cells, likely because it was complexed with heat shock proteins. As would be predicted for cells lacking appreciable levels of functional CDX2, before 4-OHT treatment, we failed to recover DNA fragments of the promoter regions of $M D R 1$ in ChIP experiments with anti-CDX2 antibody (Fig. 4A). In contrast, on day 2 after 4-OHT-mediated activation of the CDX2-ER fusion protein, we readily recovered DNA fragments containing the MDR1 promoter (Fig. 4A). The specificity of recovery of the MDR1 promoter region following ChIP with anti-CDX2 antibody was shown by the fact that other irrelevant DNA fragments lacking CDX2-binding sites (e.g., exon 3 of the $C D X 1$ gene) were not recovered (Fig. 4A). Additionally, mock immunoprecipitation (mouse IgG whole molecule) yielded few MDR1 or CDX1-specific DNA fragments (Fig. 4A). To confirm these data in endogenous CDX2, we performed the same ChIP assay in Caco2, CRC cell lines, which has strong endogenous CDX2 expression. We also recovered DNA fragments containing the MDR1 promoter region following ChIP with anti-CDX2 antibody (Fig. 4B). All these findings strongly suggest that CDX2 activates $M D R 1$ transcription by directly binding to sequences in the $5^{\prime}$ flanking region of the gene.
Figure 4. CDX2 binding to MDR1 promoter region shown by ChIP. A, CDX2 function was activated in HT-29/CDX2-ER cells by treatment of the cells with 4-OHT, and the cells were harvested at the indicated time points. B, specificity of recovery of DNA fragments of MDR1 promoter region following ChIP with anti-CDX2 antibody was confirmed in Caco2, which has endogenous strong CDX2 expression. Assays were performed in triplicate, and mean and SD values are shown.

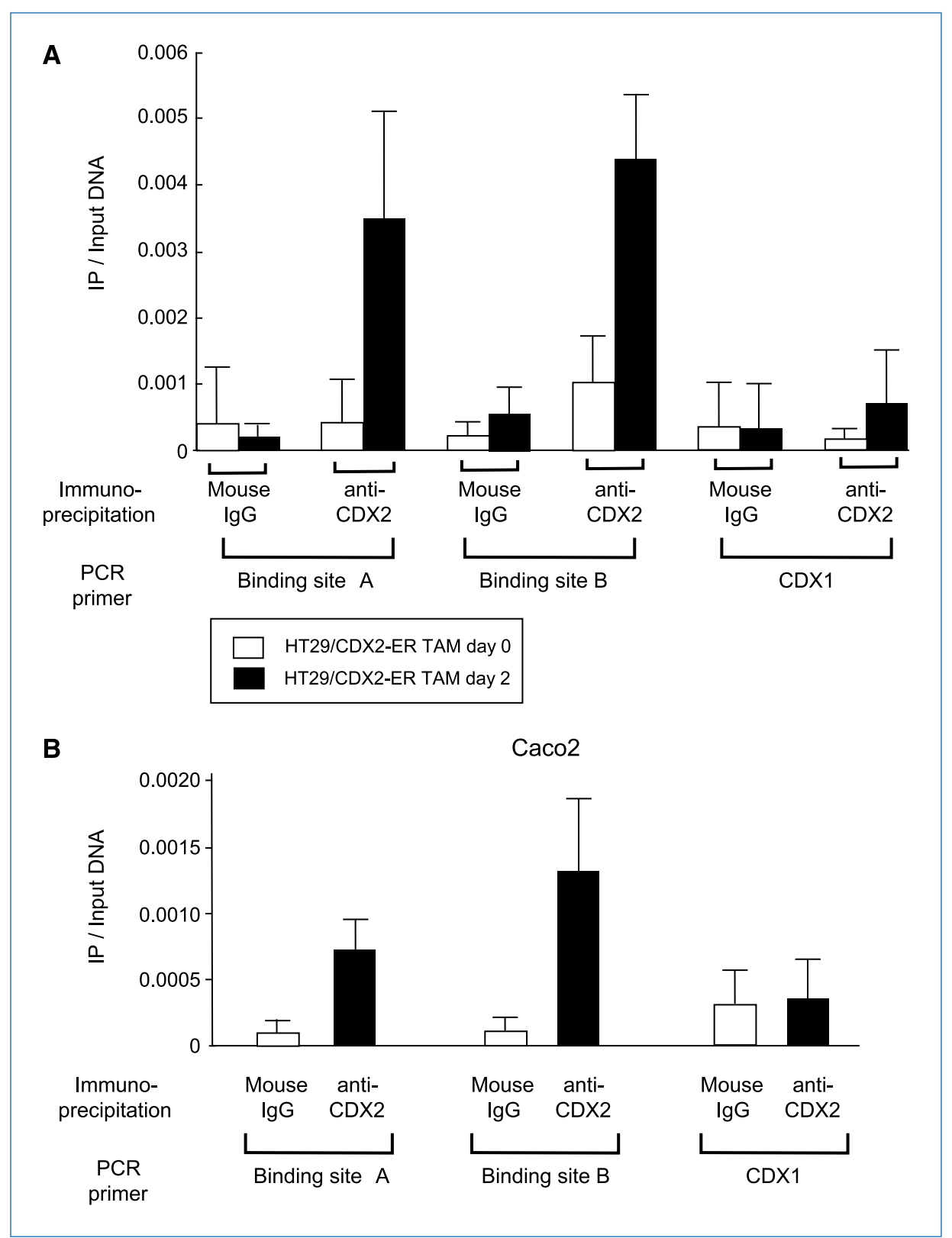




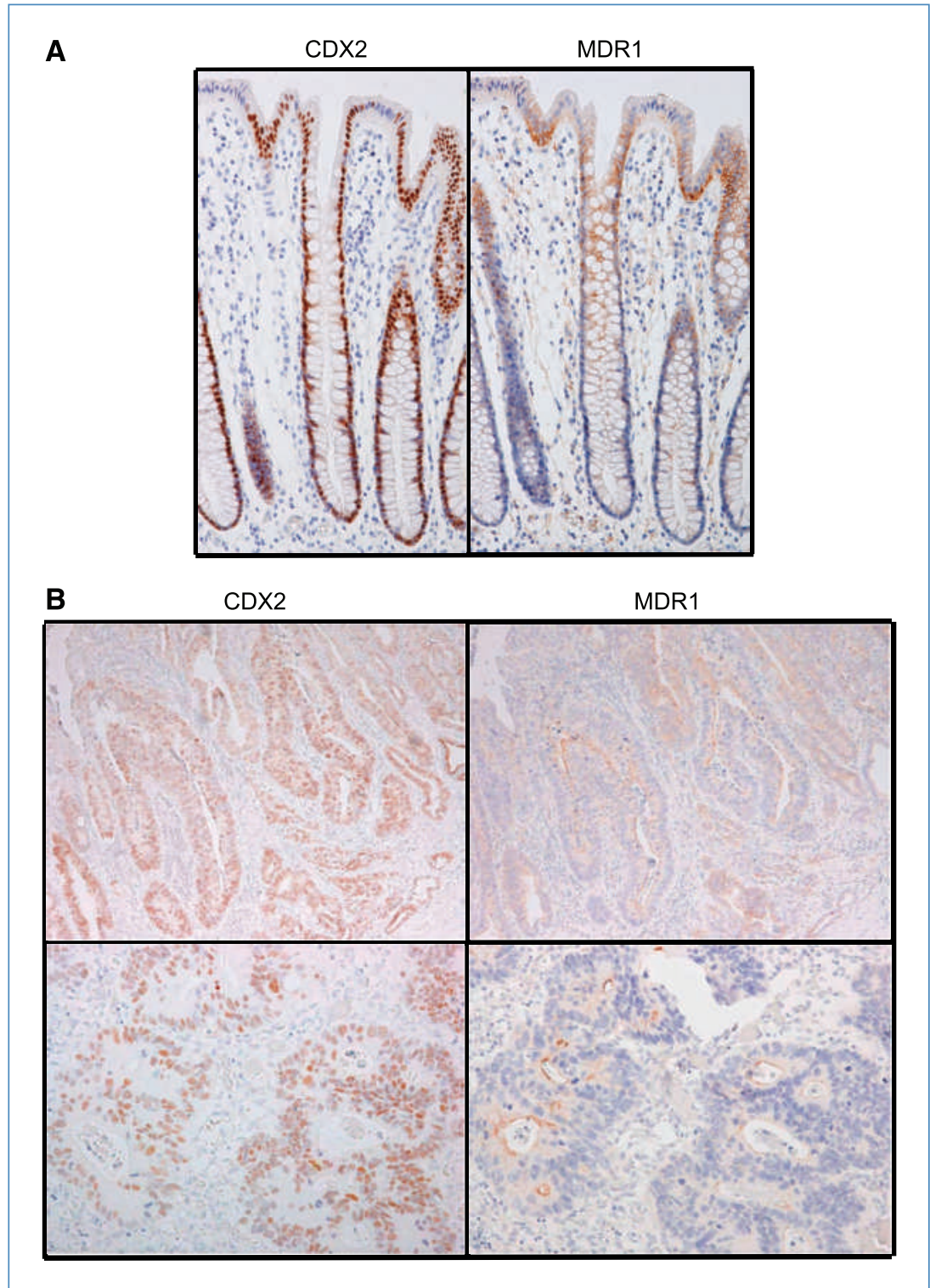

Figure 5. CDX2 and MDR1 expressions are well correlated in human colon epithelium and stomach cancer tissues. Immunohistochemistry was performed on formalin-fixed and paraffin-embedded tissues with anti-CDX2 monoclonal antibody ( $A$ and $B$, left) and with anti-MDR1 monoclonal antibody, C494 (A and $B$, right) in (A) human colon epithelium and (B) stomach cancer tissue.

\section{CDX2 and MDR1 expression are tightly coupled in neoplastic tissues in the gastrointestinal tract}

As previously noted, prior studies of CDX2 expression in normal adult tissues have shown strong CDX2 expression restricted to epithelial cells of the small intestine and colon, whereas $M D R 1$ is expressed in a broad range of normal tissues including epithelia of the liver; kidney; small and large intestine; and capillary endothelial cells in brain, ovary, and testis (25).

We examined the correlation between CDX2 and MDR1 expression in human healthy colon epithelium and CRC tissue microarray by immunohistochemical staining. Patterns of CDX2 and MDR1 expression are well correlated in normal colon epithelium (Fig. 5A). In CRC tissue microarray, we analyzed $302 \mathrm{CRC}$ tissues. For statistical comparisons, moderate and high MDR1 protein (P-glyco- protein) expression was evaluated against low MDR1 expression. In tissue microarray, 214 showed positive CDX2 expression (70.9\%), whereas 201 showed positive MDR1 expression (66.6\%). CDX2 and MDR1 expressions showed a strong positive correlation (Supplementary Table S1, $P<0.001)$. We then evaluated the correlation between CDX2 and MDR1 expression in stomach cancers because normal stomach epithelium shows low expression of both CDX2 and MDR1 $(16,26)$. CDX2 was stained intensely in nuclei of stomach cancer cells, whereas MDR1 was stained in the inner surface of neoplastic glands (Fig. 5B). Of 54 stomach cancers, 22 showed positive CDX2 expression (40.7\%), whereas 25 showed positive MDR1 expression (46.3\%). CDX2 and MDR1 expressions showed a strong positive correlation $(P<$ 0.001; Supplementary Table S2). 


\section{HT-29 cells ectopically expressing CDX2 have MDR1- dependent drug resistance}

To determine whether MDR1 induced by CDX2 functions as a drug reflux pump, we analyzed the effects of chemotherapeutic drugs on HT-29/PGS-CDX2 and HT29/PGS-neo cells (Fig. 6A). The MDR1 nonsubstrates, that is, cisplatin, camptothecin, 5-fluorouracil, and doxorubicin, showed similar activity in HT-29/PGS-CDX2 and HT-29/PGS-neo cells, whereas the known MDR1 substrates (25), vincristine and paclitaxel, showed lesser activity [7.7- and 3.0-fold increase in $\mathrm{IC}_{50}$ (72 h), respectively] in HT-29/PGS-CDX2 cells (Fig. 6A).

To examine MDR1-dependent drug resistance, we conducted the same assay in the presence of the MDR1 inhibitor verapamil. Cotreatment with $2 \mu \mathrm{mol} / \mathrm{L}$ verapamil increased the activities of vincristine and paclitaxel in HT-29/PGSCDX2 cells (Fig. 6B and C). Verapamil reduced the differences in the drug-induced cytotoxicity between HT-29/ PGS-CDX2 and HT-29/PGS-neo cells (Fig. 6B and C). This suggests that increased resistance to vincristine and paclitaxel in HT-29/PGS-CDX2 cells is caused by overexpression of the MDR1 gene.

\section{Discussion}

There is now a sizable body of data supporting the idea that the intestine-specific homeobox transcription factor CDX2 has a crucial role in directing intestinal epithelial development and differentiation $(1,2)$. However, the precise molecular mechanisms underlying tissue-specific expression of CDX2 and its downstream target genes remain undefined. To date, only a limited number of CDX2-regulated target genes have been suggested, including sucrase-isomaltase (27), glucagon (28), carbonic anhydrase 1 (29), calbindinD9K (30), vitamin D receptor (31), lactase (32), guanylyl cyclase C (33), clusterin (34), gut-enriched Krüppel-like factor (35), heparin-binding epidermal growth factor-like growth factor (36), MUC2 (37), LI-cadherin (16), HEPH (18), Cdx2 itself through autoregulatory loop (38), insulin receptor substrate 2 (39), and solute carrier family 5 , member 8 (SLC5A8; ref. 40$)$.

In this study, we identified $M D R 1$ as a candidate gene directly regulated by $\mathrm{CDX} 2$. Evidence that $\mathrm{CDX} 2$ might regulate MDR1 was initially obtained using high-density oligonucleotide microarrays to identify genes activated following overexpression of CDX2 in a CRC cell line showing very low endogenous CDX2 expression. Additionally, data indicating that endogenous MDR1 expression was dependent on CDX2 were obtained, along with evidence that activation of CDX2 induced MDR1 transcripts even in the presence of protein synthesis inhibitors. We identified four presumptive CDX2-binding sites in the 4-kb region upstream of the transcription start sites of MDR1. Reporter gene analysis showed that two of these elements were critical. Subsequent ChIP assays showed that CDX2 binds directly to this MDR1 promoter region. Immunohistochemical staining analysis for $302 \mathrm{CRCs}$ and 54 stomach cancers showed that CDX2 and MDR1 protein expressions were significantly correlated. Given the regulation of MDR1 by CDX2 in neoplastic gastrointestinal tissues, CDX2, as well as MDR1, may be a useful marker for predicting the status of drug resistance in the stomach and perhaps elsewhere.

Although our data offer reliable support for the view that CDX2 plays a role in regulating MDR1 transcription by binding to one or more elements in the proximal promoter region, CDX2 might not be sufficient for activating MDR1 expression. It is possible that other factors along with CDX2 may be required to activate $M D R 1$ transcription in certain settings, such as in HT-29 cells, because two of the eight CDX2-positive CRC cell lines we studied (namely SW48 and LS174T) expressed very low or undetectable levels of MDR1 transcripts and protein. Previously, we obtained similar evidence that CDX2 was required but not sufficient for activating LI-cadherin and HEPH transcription $(16,18)$. On the other hand, our data indicated that inhibition of CDX2 expression by siRNA leads to decreased MDR1 transcription, suggesting that CDX2 does play a key role in maintaining MDR1 expression in certain settings, such as in CDX2- and MDR1-expressing CRC cells. It will be interesting in the future to define other factors that cooperate with CDX2 in regulating MDR1, LI-cadherin, and HEPH expression in gastrointestinal tissues.

In our study, we showed that expression of CDX2 induced MDR1-dependent drug resistance in a CRC cell line, which was reversed by the MDR1-specific inhibitor verapamil (21), suggesting a role of CDX2 in the regulation of MDR1 gene expression in drug resistance. Consistent with the intestinespecific expression of CDX2 in humans and mice, recent analysis for tissue-specific murine $M d r l a$ gene expression in naïve animals revealed that the basal Mdrla expression level was 100-fold higher in the intestine than in other MDR1expressing tissues such as the liver, kidney, and spleen $(25,41)$. In epithelial cells of the lower gastrointestinal tract (jejunum, ileum, and colon), high levels of MDR1 protein are found only on the apical surfaces of superficial columnar epithelial cells, which suggests a function to prevent uptake of substrates and perhaps to facilitate excretion across the mucosa of the gastrointestinal tract (26). Given the role of CDX2 in the establishment and maintenance of intestinal epithelium, CDX2 may play a critical role in protecting the intestinal epithelium and the human body from toxic xenobiotics by stably inducing $M D R 1$ even under naïve conditions.

In cancer tissue, the $M D R 1$ gene was originally identified as an overexpressed and amplified gene in multiple drugresistant cells $(19,25)$. The $M D R 1$ gene encodes P-glycoprotein, a member of the large ATP-binding cassette superfamily of transmembrane proteins (ATP-binding cassette, sub family $B$, member 1) that transports structurally different hydrophobic chemotherapeutic agents outward in an energydependent manner. Regulation of MDR1 gene expression is complex because like many TATA-less promoters (42), the promoter of the MDR1 gene contains multiple start sites. In studies of CRCs, expression of MDR1 was correlated with pathologic grading of tumors, being most intense in welldifferentiated tumors and low in poorly differentiated ones (43). Similarly, moderately differentiated gastric carcinomas expressed a higher level of MDR1 than poorly differentiated 


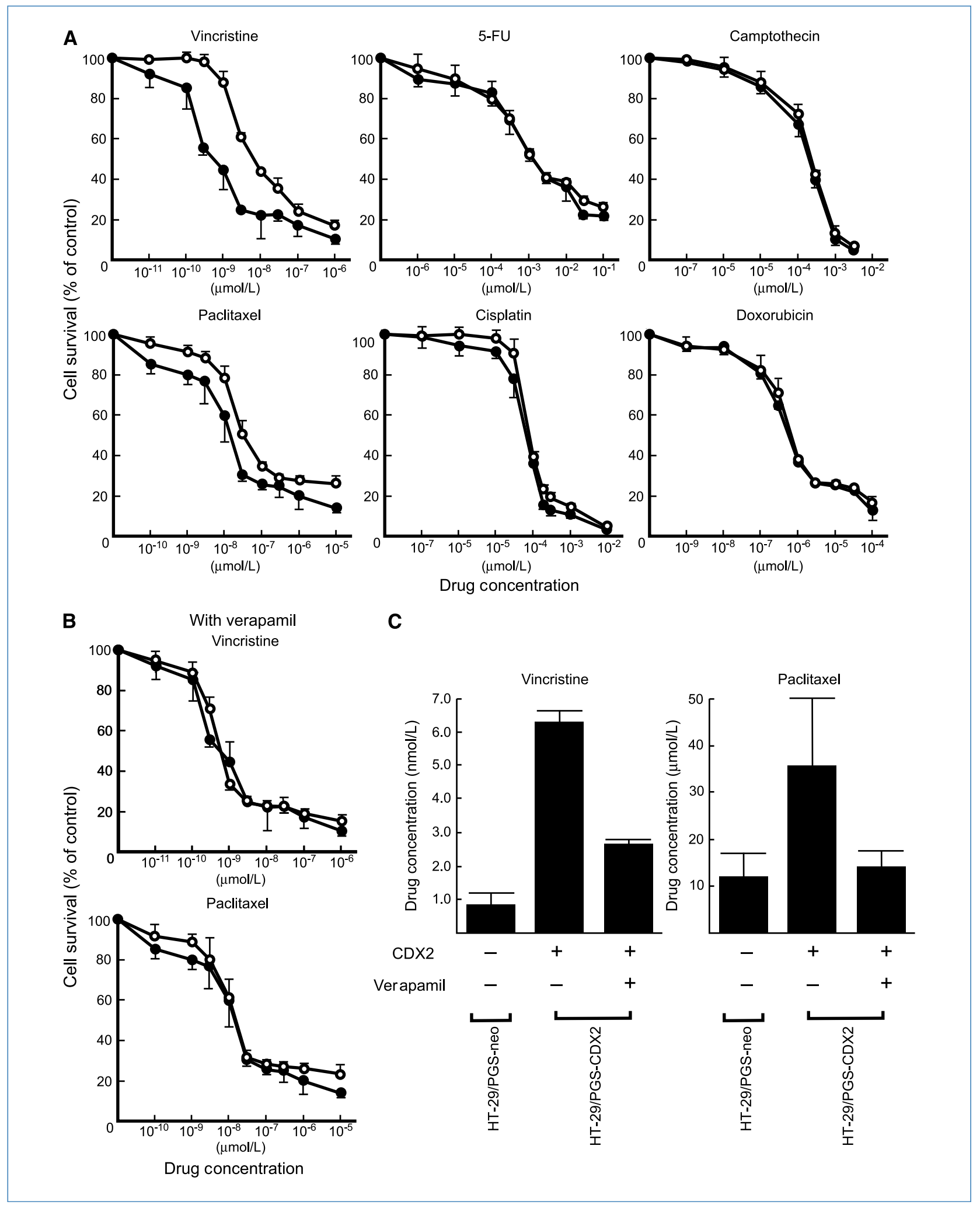

Figure 6. HT29 cells ectopically expressing CDX2 have MDR1-dependent drug resistance. A, effect of chemotherapeutic drugs on HT29/PGS-CDX2 (O)

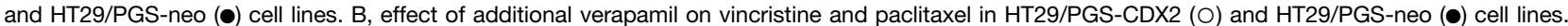
$\mathrm{C}$, $\left[\mathrm{IC}_{50}(72 \mathrm{~h})\right]$ determined by MTT assay on HT29/PGS-CDX2 and HT29/PGS-neo cells. Cotreatment with verapamil significantly recovered the sensitivity of vincristine and paclitaxel on HT-29/PGS-CDX2 cells. The cytotoxic assays were performed in triplicate; points, mean; bars, SD. 
ones (44). Although studies of CRCs arising in humans have not offered definitive proof of a causal role for CDX2 inactivation in the cancer process, it is quite clear that loss of CDX2 expression is seen in a subset of primary CRCs, particularly tumors with minimal differentiation (45). Consistent with our previous observation in large cell minimally differentiated adenocarcinoma of the colon, recent multivariate analysis also indicates that loss of CDX2 expression is associated with less-differentiated carcinoma and advanced stage, although CDX2 loss is not independently associated with patient survival $(15,46)$. Considering the roles of CDX2 in promoting cellular differentiation and inhibiting proliferation (45), CDX2 loss could conceivably contribute to aggressive tumor behavior, although MDR1 loss induced by CDX2 suppression may have some beneficial influence on patient survival with reduced drug resistance.

In conclusion, our findings implicating CDX2 in regulation of MDR1 offer data on specific factors and mechanisms regulating MDR1 expression in gastrointestinal cancers. However, several outstanding issues regarding the transcriptional regulation of $M D R 1$ by CDX2 remain to be addressed. Due to the complexity of the mechanism of drug resistance, further studies of MDR1 and its regulation by CDX2 in various

\section{References}

1. Silberg DG, Swain GP, Suh ER, Traber PG. Cdx1 and cdx2 expression during intestinal development. Gastroenterology 2000;119:961-71.

2. Beck $F$. The role of $C d x$ genes in the mammalian gut. Gut 2004;53: 1394-6.

3. Moreno E, Morata G. Caudal is the Hox gene that specifies the most posterior Drosophile segment. Nature 1999;400:873-7.

4. Macdonald PM, Struhl G. A molecular gradient in early Drosophila embryos and its role in specifying the body pattern. Nature 1986; 324:537-45.

5. Niwa $\mathrm{H}$, Toyooka $\mathrm{Y}$, Shimosato $\mathrm{D}$, et al. Interaction between Oct3/4 and Cdx2 determines trophectoderm differentiation. Cell 2005;123: 917-29.

6. Tolkunova E, Cavaleri F, Eckardt $\mathrm{S}$, et al. The caudal-related protein cdx2 promotes trophoblast differentiation of mouse embryonic stem cells. Stem Cells 2006;24:139-44.

7. Chawengsaksophak K, James R, Hammond VE, Kontgen F, Beck F. Homeosis and intestinal tumours in Cdx2 mutant mice. Nature 1997; 386:84-7.

8. Tamai $Y$, Nakajima R, Ishikawa T, Takaku K, Seldin MF, Taketo MM. Colonic hamartoma development by anomalous duplication in $\mathrm{Cdx} 2$ knockout mice. Cancer Res 1999;59:2965-70.

9. Bonhomme C, Duluc I, Martin E, et al. The Cdx2 homeobox gene has a tumour suppressor function in the distal colon in addition to a homeotic role during gut development. Gut 2003;52:1465-71.

10. Aoki K, Tamai Y, Horiike S, Oshima M, Taketo MM. Colonic polyposis caused by mTOR-mediated chromosomal instability in Apc $+/ \Delta 716 \mathrm{Cdx2}+/-$ compound mutant mice. Nat Genet 2003; 35:323-30.

11. Beck F, Chawengsaksophak K, Waring P, Playford RJ, Furness JB. Reprogramming of intestinal differentiation and intercalary regeneration in Cdx2 mutant mice. Proc Natl Acad Sci U S A 1999;96: 7318-23.

12. Silberg DG, Sullivan J, Kang E, et al. Cdx2 ectopic expression induces gastric intestinal metaplasia in transgenic mice. Gastroenterology 2002;122:689-96.

13. Mutoh $\mathrm{H}$, Hakamata $\mathrm{Y}$, Sato $\mathrm{K}$, et al. Conversion of gastric mucosa to intestinal metaplasia in Cdx2-expressing transgenic mice. Biochem Biophys Res Commun 2002;294:470-9.

14. Ee HC, Erler T, Bhathal PS, Young GP, James RJ. Cdx-2 homeodo- gastrointestinal cancers should help to enhance understanding of the mechanism of aberrant (ectopic) expression of CDX2 and its downstream target MDR1, and in the development of a strategy to select chemotherapy regimens based on the status of CDX2 and MDR1 expression.

\section{Disclosure of Potential Conflicts of Interest}

No potential conflicts of interest were disclosed.

\section{Acknowledgments}

We thank Drs. Hideki Yamamoto and Yoshitaka Tomoda for their advice, Yuko Ishida and Midori Kiyokawa for their expert technical assistance, and the Analysis Center of Life Science, Hiroshima University, for the use of their facilities.

\section{Grant Support}

US NIH grants CA082223. NIH R01CA082223 (E.R. Fearon).

The costs of publication of this article were defrayed in part by the payment of page charges. This article must therefore be hereby marked advertisement in accordance with 18 U.S.C. Section 1734 solely to indicate this fact.

Received 12/30/2009; revised 05/27/2010; accepted 06/11/2010; published OnlineFirst 08/10/2010.

main protein expression in human and rat colorectal adenoma and carcinoma. Am J Pathol 1995;147:586-92.

15. Hinoi T, Tani M, Lucas PC, et al. Loss of CDX2 expression and microsatellite instability are prominent features of large cell minimally differentiated carcinomas of the colon. Am J Pathol 2001;159: 2239-48.

16. Hinoi T, Lucas PC, Kuick R, Hanash S, Cho KR, Fearon ER. CDX2 regulates liver intestine-cadherin expression in normal and malignant colon epithelium and intestinal metaplasia. Gastroenterology 2002; 123:1565-77.

17. Eda A, Osawa H, Yanaka I, et al. Expression of homeobox gene CDX2 precedes that of CDX1 during the progression of intestinal metaplasia. J Gastroenterol 2002;37:94-100.

18. Hinoi T, Gesina G, Akyol A, et al. CDX2-regulated expression of iron transport protein hephaestin in intestinal and colonic epithelium. Gastroenterology 2005;128:946-61.

19. Pastan I, Gottesman MM. Multidrug resistance. Annu Rev Med 1991; 42:277-86.

20. Littlewood TD, Hancock DC, Danielian PS, Parker MG, Evan GI. A modified oestrogen receptor ligand-binding domain as an improved switch for the regulation of heterologous proteins. Nucleic Acids Res 1995;23:1686-90.

21. Tsuruo $T$, lida $H$, Tsukagoshi $S$, Sakurai $Y$. Overcoming of vincristine resistance in P388 leukemia in vivo and in vitro through enhanced cytotoxicity of vincristine and vinblastine by verapamil. Cancer Res 1981;41:1967-72.

22. Mallo GV, Soubeyran P, Lissitzky JC, et al. Expression of the Cdx1 and $\mathrm{Cdx} 2$ homeotic genes leads to reduced malignancy in colon cancer-derived cells. J Biol Chem 1998;273:14030-6.

23. Margalit $Y$, Yarus $S$, Shapira $E$, Gruenbaum $Y$, Fainsod $A$. Isolation and characterization of target sequences of the chicken CdxA homeobox gene. Nucleic Acids Res 1993;21:4915-22.

24. Heinemeyer $T$, Wingender $E$, Reuter I, et al. Databases on transcriptional regulation: TRANSFAC, TRRD and COMPEL. Nucleic Acids Res 1998;26:362-7.

25. Ambudkar SV, Dey S, Hrycyna CA, Ramachandra M, Pastan I, Gottesman MM. Biochemical, cellular, and pharmacological aspects of the multidrug transporter. Annu Rev Pharmacol Toxicol 1999;39:361-98. 
26. Thiebaut F, Tsuruo $T$, Hamada $H$, Gottesman MM, Pastan I, Willingham MC. Cellular localization of the multidrug-resistance gene product P-glycoprotein in normal human tissues. Proc Natl Acad Sci U S A 1987;84:7735-8.

27. Suh E, Chen L, Taylor J, Traber PG. A homeodomain protein related to caudal regulates intestine-specific gene transcription. Mol Cell Biol 1994;14:7340-51.

28. Jin T, Trinh DK, Wang F, Drucker DJ. The caudal homeobox protein $c d x-2 / 3$ activates endogenous proglucagon gene expression in InR1-9 islet cells. Mol Endocrinol 1997;11:203-9.

29. Drummond FJ, Sowden J, Morrison K, Edwards YH. Colon carbonic anhydrase 1: transactivation of gene expression by the homeodomain protein Cdx2. FEBS Lett 1998;423:218-22.

30. Colnot S, Romagnolo B, Lambert M, et al. Intestinal expression of the calbindin-D9K gene in transgenic mice. Requirement for a Cdx2binding site in a distal activator region. J Biol Chem 1998;273: 31939-46.

31. Yamamoto H, Miyamoto K, Li B, et al. The caudal-related homeodomain protein $\mathrm{Cdx}-2$ regulates vitamin $\mathrm{D}$ receptor gene expression in the small intestine. J Bone Miner Res 1999;14:240-7.

32. Fang R, Santiago NA, Olds LC, Sibley E. The homeodomain protein $\mathrm{Cdx} 2$ regulates lactase gene promoter activity during enterocyte differentiation. Gastroenterology 2000;118:115-27.

33. Park J, Schulz S, Waldman SA. Intestine-specific activity of the human guanylyl cyclase $\mathrm{C}$ promoter is regulated by $\mathrm{Cdx2}$. Gastroenterology 2000;119:89-96.

34. Suh E, Wang Z, Swain GP, Tenniswood M, Traber PG. Clusterin gene transcription is activated by caudal-related homeobox genes in intestinal epithelium. Am J Physiol Gastrointest Liver Physiol 2001; 280:G149-56.

35. Dang DT, Mahatan CS, Dang LH, Agboola IA, Yang VW. Expression of the gut-enriched Kruppel-like factor (Kruppel-like factor 4) gene in the human colon cancer cell line RKO is dependent on CDX2. Oncogene 2001;20:4884-90.

36. Uesaka T, Lu H, Katoh O, Watanabe H. Heparin-binding EGF-like growth factor gene transcription regulated by $\mathrm{Cdx} 2$ in the intestinal epithelium. Am J Physiol Gastrointest Liver Physiol 2002;283: G840-7.

37. Yamamoto $H$, Bai YQ, Yuasa Y. Homeodomain protein CDX2 regulates goblet-specific MUC2 gene expression. Biochem Biophys Res Commun 2003;300:813-8.

38. Xu F, Li H, Jin T. Cell type-specific autoregulation of the Caudalrelated homeobox gene Cdx-2/3. J Biol Chem 1999;274:34310-6.

39. Modica S, Morgano A, Salvatore L, et al. Expression and localisation of insulin receptor substrate 2 in normal intestine and colorectal tumours. Regulation by intestine-specific transcription factor CDX2. Gut 2009;58:1250-9.

40. Kakizaki F, Aoki K, Miyoshi H, Carrasco N, Aoki M, Taketo MM. CDX transcription factors positively regulate expression of solute carrier family 5 , member 8 in the colonic epithelium. Gastroenterology 2010;138:627-35.

41. Gu L, Tsark WM, Brown DA, Blanchard S, Synold TW, Kane SE. A new model for studying tissue-specific mdr1a gene expression in vivo by live imaging. Proc Natl Acad Sci U S A 2009;106:5394-9.

42. Labialle S, Gayet L, Marthinet E, Rigal D, Baggetto LG. Transcriptional regulators of the human multidrug resistance 1 gene: recent views. Biochem Pharmacol 2002;64:943-8.

43. Potocnik U, Ravnik-Glavac M, Golouh R, Glavac D. Naturally occurring mutations and functional polymorphisms in multidrug resistance 1 gene: correlation with microsatellite instability and lymphoid infiltration in colorectal cancers. J Med Genet 2002;39:340-6.

44. Mizoguchi T, Yamada K, Furukawa T, et al. Expression of the MDR1 gene in human gastric and colorectal carcinomas. J Natl Cancer Inst 1990;82:1679-83.

45. Hinoi T, Loda M, Fearon ER. Silencing of CDX2 expression in colon cancer via a dominant repression pathway. J Biol Chem 2003;278: 44608-16.

46. Baba Y, Nosho K, Shima K, et al. Relationship of CDX2 loss with molecular features and prognosis in colorectal cancer. Clin Cancer Res 2009;15:4665-73. 


\section{CDX2 Regulates Multidrug Resistance 1 Gene Expression in Malignant Intestinal Epithelium}

Yuji Takakura, Takao Hinoi, Naohide Oue, et al.

Cancer Res 2010;70:6767-6778. Published OnlineFirst August 10, 2010.

Updated version Access the most recent version of this article at: doi:10.1158/0008-5472.CAN-09-4701

Supplementary Access the most recent supplemental material at:

Material http://cancerres.aacrjournals.org/content/suppl/2010/08/09/0008-5472.CAN-09-4701.DC1

Cited articles This article cites 46 articles, 15 of which you can access for free at: http://cancerres.aacrjournals.org/content/70/17/6767.full\#ref-list-1

Citing articles This article has been cited by 1 HighWire-hosted articles. Access the articles at:

http://cancerres.aacrjournals.org/content/70/17/6767.full\#related-urls

E-mail alerts Sign up to receive free email-alerts related to this article or journal.

Reprints and To order reprints of this article or to subscribe to the journal, contact the AACR Publications Subscriptions Department at pubs@aacr.org.

Permissions To request permission to re-use all or part of this article, use this link http://cancerres.aacrjournals.org/content/70/17/6767.

Click on "Request Permissions" which will take you to the Copyright Clearance Center's (CCC) Rightslink site. 